\title{
Effects of sintering temperature on grain growth and the complex permeability of Co0.2Ni0.3Zn0.5Fe2O4 material prepared using mechanically alloyed nanoparticles.
}

\begin{abstract}
Nanoparticle-sized $\mathrm{Co} 0.2 \mathrm{Ni0} .3 \mathrm{Zn} 0.5 \mathrm{Fe} 2 \mathrm{O} 4$ was prepared using mechanical alloying and sintering. The starting raw materials were milled in air and subsequently sintered at various temperatures from 600 to $1300{ }^{\circ} \mathrm{C}$. The effects of sintering temperature on physical, magnetic and electrical characteristics were studied. The complex permittivity and permeability were investigated in the frequency range $10 \mathrm{MHz}$ to $1.0 \mathrm{GHz}$. The results show that single phase $\mathrm{Co} 0.2 \mathrm{Ni} 0.3 \mathrm{Zn} 0.5 \mathrm{Fe} 2 \mathrm{O} 4$ could not be formed during milling alone and therefore requires sintering. The crystallization of the ferrite sample increases with increasing sintering temperature; which decrease the porosity and increase the density, crystallite size and the shrinkage of the material. The maximum magnetization value of $83.1 \mathrm{emu} / \mathrm{g}$ was obtained for a sample sintered at $1200{ }^{\circ} \mathrm{C}$, while both the retentivity and the coercivity decrease with increasing the sintering temperature. The permeability values vary with both the sintering temperature and the frequency and the absolute value of the permeability decreased after the natural resonance frequency. The real part of the permittivity was constant within the measured frequency, while the loss tangent values decreased gradually with increasing frequency.
\end{abstract}

Keyword: Mechanical alloying; Sintering; Nanoparticles; Permeability. 